\title{
Determination of Optimal Manufacturing Parameters for Injection Mold by Inverse Model Basing on MANFIS
}

\author{
Chung-Neng Huang ${ }^{1}$, Chong-Ching Chang ${ }^{2}$ \\ Graduate Institute of Mechatronic System Engineering, National University of Tainan, Tainan, Taiwan, China. \\ Email: kosono@mail.nutn.edu.tw,jeff0718@mail.nutn.edu.tw \\ Received October $29^{\text {th }}, 2009$; accepted January $11^{\text {th }}, 2010$.
}

\begin{abstract}
Since plastic products are with the features as light, anticorrosive and low cost etc., that are generally used in several of tools or components. Consequently, the requirements on the quality and effectiveness in production are increasingly serious. However, there are many factors affecting the yield rate of injection products such as material characteristic, mold design, and manufacturing parameters etc. involved with injection machine and the whole manufacturing process. Traditionally, these factors can only be designed and adjusted by many times of trial-and-error tests. It is not only waste of time and resource, but also lack of methodology for referring. Although there are some methods as Taguchi method or neural network etc. proposed for serving and optimizing this problem, they are still insufficient for the needs. For the reasons, a method for determining the optimal parameters by the inverse model of manufacturing platform is proposed in this paper. Through the integration of inverse model basing on MANFIS and Taguchi method, inversely, the optimal manufacturing parameters can be found by using the product requirements. The effectiveness and feasibility of this proposal is confirmed through numerical studies on a real case example.
\end{abstract}

Keywords: Optimal Manufacturing Parameter, Injection Mold, Multiple Adaptive Network Based Fuzzy Inference System (Manfis), Taguchi Method

\section{Introduction}

Recently for the surge in the prices of fuel and raw materials like steel or iron, plastic goods used in industries and everyday life are taking the place of metal ones. Generally, since those products combined by pieces of parts required higher precision and smoothness, the demands on quality and efficiency of production become higher than before. In order to level up the yield rate of made-up articles, the manufacturing process should be improved for the required of different goods [1]. Nowadays, for coping with the diversifying demands of present markets, developed countries in industry have been introducing the technologies of computer-integrated manufacture (CIM) as CAE/CAD/CAM to get competitive advantages [2-3]. That is, for the manufacturing process of an industrial product with completed design, first, its prototype is designed by the original concept. Next, through computer-aided design (CAD) tool complete the initial design. Third, by the analysis technology of computer-aided engineering (CAE) to test and modify the design. Finally, depending on the better design, automotive production can be done by computer-aided manufacture (CAM).

Before concurrent engineering attracting much attention, the technologies of computer-aided engineering analysis were seldom used to estimate designing faults by manufacturers in advance. Where, mold design and manufacturing process should be modified through many times of trial-and-error tests [4-6]. It not only wastes time and cost but also makes such experiences became more difficult in teaching or accumulating. Besides, under the situation of different product required or new materials, the awkward problems as one more times of teaching experience and molding can not be avoided. Sometimes part of business chances may be losing for it.

The most helpful function of CAE is to carry out simulation analysis of prototype design by computers [6]. By which, all possible problems and faults occurring in manufacturing and design stages can be found in advance. It is convenient to diagnose and modify designed before product manufacture for reducing cost and time, and lev- 
eling up quality. However, even though those modern computer-aided technologies as mentioned above play an important role in manufacture, the subject of how to determine optimal manufacturing parameters for extremely matching product required still exists [7-24]. Although there are a lot of methods such as statistical regression calculation, neural network model and genetic algorithm, grey relational analysis, and fuzzy theory etc. proposed for optimizing parameters [25-30], lacking of methodology and integration. For it, a concept for building the inverse model of manufacturing platforms by multiple adaptive network fuzzy inference system (MANFIS) is proposed. Through data self-organized and deductive reasoning mechanisms of MANFIS, the optimal manufacturing parameters corresponding to product required can be found. In this paper, the blade of a small-scale wind power generator is selected as a real case studying on injection mold. Through the simulation results by computer-aided analysis software Moldex3D, the appropriateness and effectiveness of the proposal can be confirmed.

\section{Solution Design and Problem Statement}

\subsection{Solution Description}

The main purpose of this study is to determine the optimal manufacturing parameters for injection mold. According to the literatures mentioned above know that the manufacturing parameters of injection mold are highly interdependent. That is, the whole system should be considered while part of parameters is undertaken to modify. Here, a method for finding out the optimal parameters is proposed. Figure 1 shows the executing flow of the method. First, since there are always a lot of manufacturing parameters as well as controllable factors existing, in order to realize which ones are the key factors and

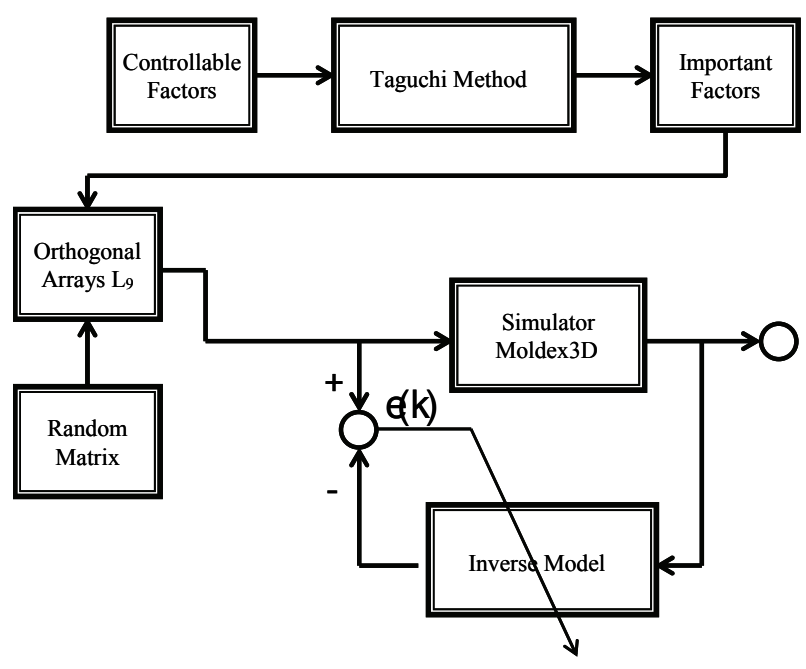

Figure 1. Flow of proposed method reduce time and flows in computation, a less number of important factors with more controllability can be extracted through the calculation of Taguchi method. Next, instead of all possible experimental combinations to simulator, the orthogonal arrays basing on those important factors are developed. In addition, for the results found by Taguchi method are unique, and possibly trapping in local optimum, a decimal-fraction random matrix as the numerical stirring is introduced into the orthogonal arrays for wider-range simulation. Finally, by using the simulated results such as warpage displacement or volumetric shrinkage etc. along with the corresponded orthogonal arrays, the proposed inverse model can be built through MANFIS.

\subsection{Real Case Selection}

The real case selected for confirming the proposed method is the manufacturing design of a blade for a small-scale wind power generator. Since the blades are the key part of such generators for their generation efficiency and cost, the weight, smoothness, surface friction, physical stress, and twisting angles etc. of them are required seriously in manufacture. In addition, instead of FRP which is denounced by its environmental pollution, the material ABS_NovodurP2GHV_1 is adopted to study. Here, through the analysis of momentum theory and blade element model, the geometric data of the blade is determined as shown in Figure 2. Moreover, the hot and cooling distributions by one-point injection and four groups of cooling runners are shown in Figure 3.

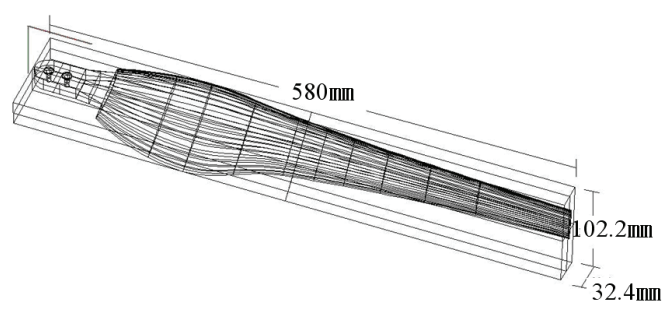

Figure 2. Studying case designed by 3D's flow

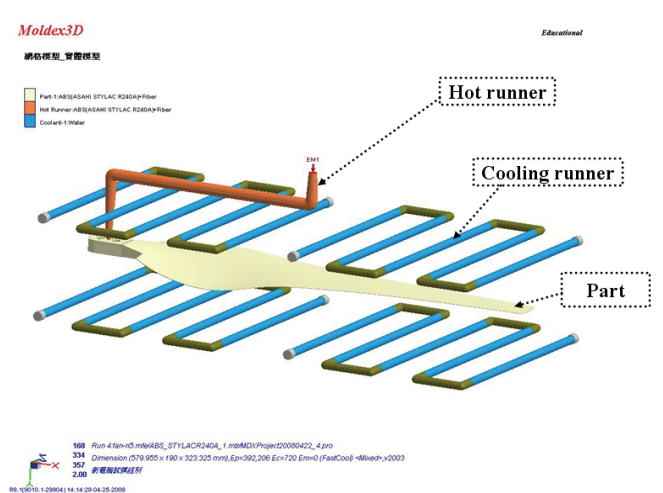

Figure 3. Distribution of hot runner and cooling runner 


\section{Numerical Studies}

Since the initial controllable factors are always selected by the product required. Through the analysis of fish bone diagram shown in Figure 4 and the consideration of required product strength, there are eight factors selected such as fiber percentage of material, material temperature, injection pressure, holding time, holding pressure, mold temperature, cooling time, and filling time.

\subsection{Selection of Important Factors by Taguchi Method}

Two major tools used in the Taguchi method are the orthogonal arrays and the signal-to-noise ratio. Additional details and application of Taguchi method can be found in the books presented by Phadke [31], Montgomery [32], and Park [33]. In this paper, three- level orthogonal arrays are used. The design parameters and the levels chosen for the Taguchi experiments are listed in Table1. Continuously, a $\mathrm{L}_{18}\left(3^{8}\right)$ orthogonal arrays with eight columns and eighteen rows can be developed as shown in Table 2. Each design parameter has three levels assigned to each column of the arrays. The eighteen rows represent the eighteen experiments to be conducted.

Since the assessing indices are the warpage displacements and volumetric shrinkages in three dimensions as $\mathrm{x}, \mathrm{y}$, and $\mathrm{z}$ axes, respectively, through the computations of simulator Moldex3D all indices corresponding to all experimental combinations in $\mathrm{L}_{18}\left(3^{8}\right)$ orthogonal arrays can be found. By substituting these indices into Equations

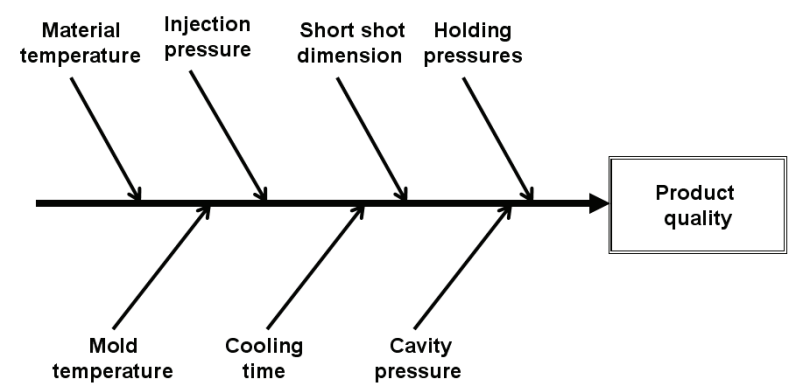

Figure 4. Fish bone diagram for factor analysis

Table 1. Eight controllable factors with three levels

\begin{tabular}{lccc}
\hline \multicolumn{1}{c}{ factor } & 1 & 2 & 3 \\
\hline A. $(\%)$ percentage of fiber contents & 20 & 16 & \\
B. $\left({ }^{\circ} \mathrm{C}\right)$ material temperature & 210 & 225 & 240 \\
C. $(\mathrm{MPa})$ injection pressure & 90 & 105 & 120 \\
D. $(\mathrm{S})$ holding time & 2 & 4 & 6 \\
E. $(\mathrm{MPa})$ holding pressure & 63 & 73.5 & 84 \\
F. $\left({ }^{\circ} \mathrm{C}\right)$ mold temperature & 50 & 70 & 87 \\
G. $(\mathrm{S})$ cooling time & 10 & 20 & 30 \\
H. $(\mathrm{S})$ filling time & 2.3 & 3.65 & 5 \\
\hline
\end{tabular}

1 to 3 , the important factors and optimal combination for Taguchi method can be extracted and found by assessing the quality characteristic (in Figure 5) and signal-to-noise ratio (in Figure 6). By above results realized that the factors with more controllability as mold temperature, material temperature, injection pressure, and holding time are selected as the important factors.

$$
\begin{gathered}
\bar{y}=\frac{\sum_{i=1}^{n} y_{i}}{n} \\
S=\sqrt{\frac{\sum_{i=1}^{n}\left(y_{i}-\bar{y}\right)^{2}}{n-1}} \\
S / N=-10 \log \frac{S^{2}}{y}
\end{gathered}
$$

\subsection{Collection of Training Data Sets}

For training the inverse model to be with more comprehensively deductive reasoning, all possible combinations basing on the changes of four important factors should be collected in general. However, it would be a cumbersome task for experiment or computation. For the main advantages of orthogonal arrays including experimental plan simplification and feasibility of studying interaction effects among the different parameters, a $\mathrm{L}_{9}\left(3^{4}\right)$ orthogonal arrays developing with three levels (Table 3 ) from above four important factors is built as shown in Table 4. Moreover, for more detailed numerical data, a random matrix (Table 5) as well as a stirring is introduced into the $\mathrm{L}_{9}\left(3^{4}\right)$ orthogonal arrays. Table 6 shows the input-output training data sets through the computation of simulator Moldex3D.

Table 2. $\mathrm{L}_{18}\left(3^{8}\right)$ orthogonal arrays

\begin{tabular}{ccccccccc}
\hline Exp & A & B & C & D & E & F & G & H \\
\hline 1 & 1 & 1 & 1 & 1 & 1 & 1 & 1 & 1 \\
2 & 1 & 1 & 2 & 2 & 2 & 2 & 2 & 2 \\
3 & 1 & 1 & 3 & 3 & 3 & 3 & 3 & 3 \\
4 & 1 & 2 & 1 & 1 & 2 & 2 & 3 & 3 \\
5 & 1 & 2 & 2 & 2 & 3 & 3 & 1 & 1 \\
6 & 1 & 2 & 3 & 3 & 1 & 1 & 2 & 2 \\
7 & 1 & 3 & 1 & 2 & 1 & 3 & 2 & 3 \\
8 & 1 & 3 & 2 & 3 & 2 & 1 & 3 & 1 \\
9 & 1 & 3 & 3 & 1 & 3 & 2 & 1 & 2 \\
10 & 2 & 1 & 1 & 3 & 3 & 2 & 2 & 1 \\
11 & 2 & 1 & 2 & 1 & 1 & 3 & 3 & 2 \\
12 & 2 & 1 & 3 & 2 & 2 & 1 & 1 & 3 \\
13 & 2 & 2 & 1 & 2 & 3 & 1 & 3 & 2 \\
14 & 2 & 2 & 2 & 3 & 1 & 2 & 1 & 3 \\
15 & 2 & 2 & 3 & 1 & 2 & 3 & 2 & 1 \\
16 & 2 & 3 & 1 & 3 & 2 & 3 & 1 & 2 \\
17 & 2 & 3 & 2 & 1 & 3 & 1 & 2 & 3 \\
18 & 2 & 3 & 3 & 2 & 1 & 2 & 3 & 1 \\
\hline
\end{tabular}




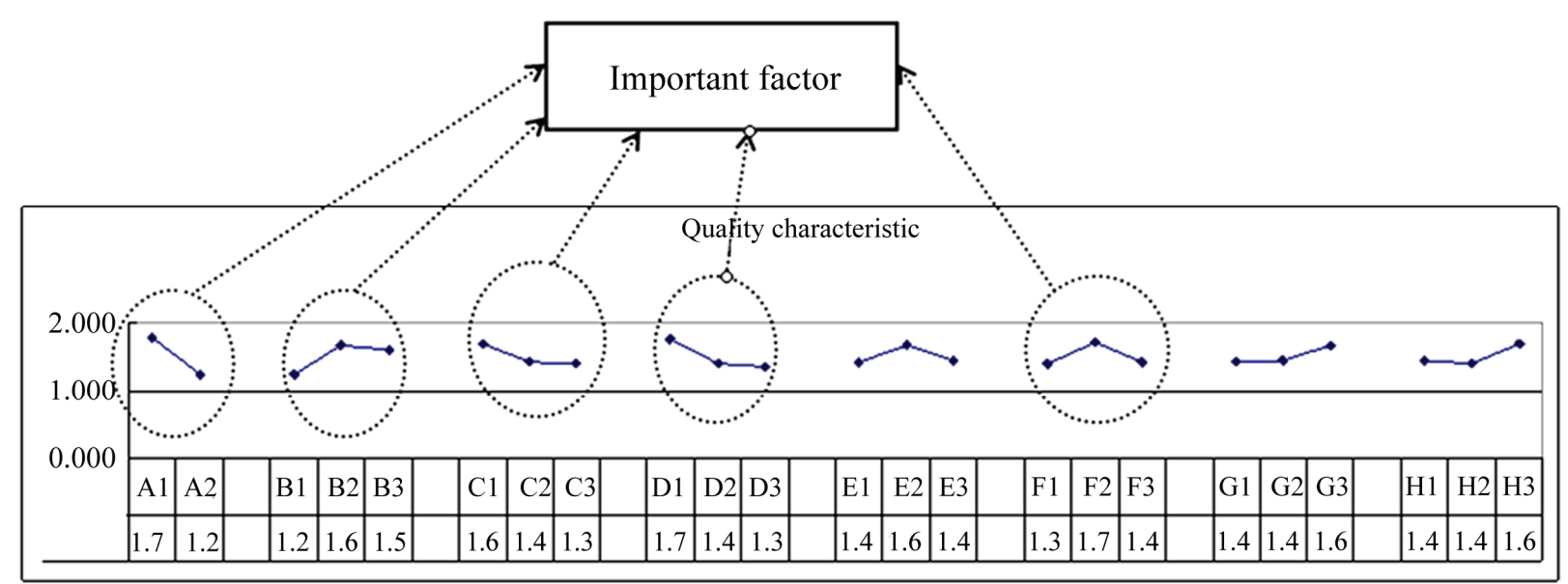

Figure 5. Quality characteristic (2、B1、C3、D3、E1、F1、G1、H2)

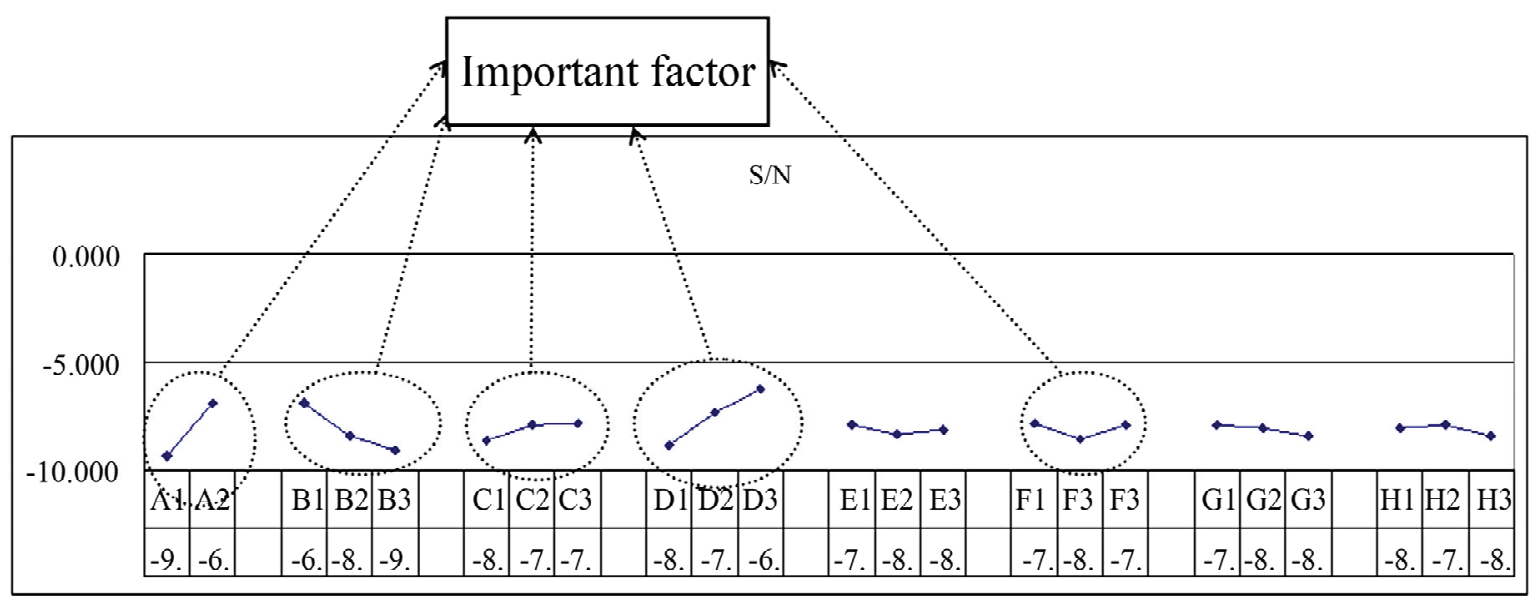

Figure 6. S/N ratio (A2、B1、C3、D3、E1、F1、G1、H2)

Table 3. Four important factors with three levels

\begin{tabular}{lccc}
\hline \multicolumn{1}{c}{ level } & 1 & 2 & 3 \\
\hline B. $\left({ }^{\circ} \mathrm{C}\right)$ material temperature & 220 & 240 & 260 \\
C. $(\mathrm{MPa})$ injection pressure & 110 & 120 & 130 \\
D. $(\mathrm{S})$ holding time & 4 & 6 & 8 \\
F. $\left({ }^{\circ} \mathrm{C}\right)$ mold temperature & 45 & 50 & 55 \\
\hline
\end{tabular}

Table 4. $L_{9}\left(3^{4}\right)$ orthogonal arrays

\begin{tabular}{ccccc}
\hline Exp & B & C & D & F \\
\hline 1 & 1 & 1 & 1 & 1 \\
2 & 1 & 2 & 2 & 2 \\
3 & 1 & 3 & 3 & 3 \\
4 & 2 & 1 & 2 & 3 \\
5 & 2 & 2 & 3 & 1 \\
6 & 2 & 3 & 1 & 2 \\
7 & 3 & 1 & 3 & 2 \\
8 & 3 & 2 & 1 & 3 \\
9 & 3 & 3 & 2 & 1 \\
\hline
\end{tabular}

Table 5. Random matrix example

\begin{tabular}{cccc}
\hline 0.95 & 0.2311 & 0.6068 & 0.486 \\
\hline 0.891 & 0.7621 & 0.4565 & 0.0185 \\
0.821 & 0.4447 & 0.6154 & 0.7919 \\
0.922 & 0.7382 & 0.1763 & 0.4057 \\
0.935 & 0.9169 & 0.4103 & 0.8937 \\
0.058 & 0.3529 & 0.8132 & 0.0099 \\
0.139 & 0.2028 & 0.1987 & 0.6038 \\
0.272 & 0.1988 & 0.0153 & 0.7468 \\
0.445 & 0.9318 & 0.466 & 0.4187 \\
\hline
\end{tabular}

\subsection{Inverse Model}

The proposed inverse model for finding out the optimal manufacturing parameters corresponding to product required is built by MANFIS (in Figure 7), which is an extension of ANFIS to produce multiple real responses of the target system. The number of ANFIS is equal to the number $n$ of responses. ANFIS is a fuzzy inference 
Table 6. Training data sets for MANFIS

\begin{tabular}{ccccccccc}
\hline exp & B & C & D & F & X & Y & Z & V \\
\hline 1 & 220.9 & 110.2 & 4.6 & 45.4 & 0.402 & 0.053 & -0.129 & 4.14 \\
2 & 220.8 & 120.7 & 6.4 & 50.0 & 0.581 & 0.058 & -0.109 & 3.962 \\
3 & 220.8 & 130.4 & 8.6 & 55.7 & 0.302 & 0.132 & -0.038 & 3.774 \\
4 & 240.9 & 110.7 & 6.1 & 55.4 & 0.326 & 0.017 & -0.083 & 4.774 \\
5 & 240.9 & 120.9 & 8.4 & 45.8 & 0.358 & 0.004 & -0.106 & 4.568 \\
6 & 240.0 & 130.3 & 4.8 & 50.0 & 0.577 & -0.041 & -0.137 & 4.888 \\
7 & 260.1 & 110.2 & 8.1 & 50.6 & 0.305 & 0.028 & -0.166 & 5.32 \\
8 & 260.2 & 120.2 & 4.0 & 55.7 & 0.483 & -0.068 & -0.238 & 5.796 \\
9 & 260.4 & 130.9 & 6.4 & 45.4 & 0.69 & 0.096 & -0.131 & 5.515 \\
\hline
\end{tabular}

$\mathrm{X}$ : warpage displacement in $\mathrm{X}$ axis

$\mathrm{Y}$ : warpage displacement in $\mathrm{y}$ axis

$\mathrm{Z}$ : warpage displacement in $\mathrm{z}$ axis

$\mathrm{V}$ : warpage-volumetric shrinkage

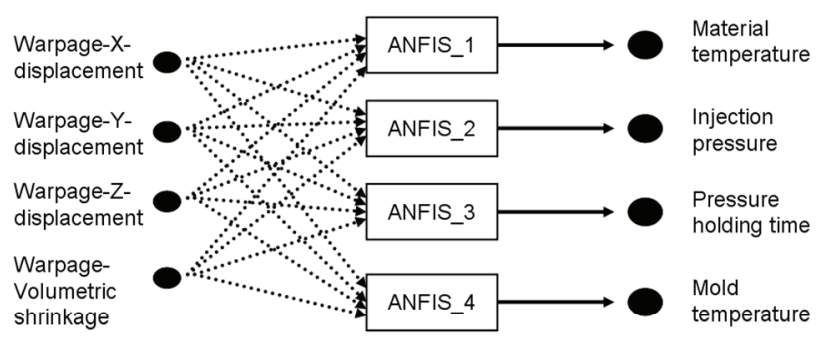

Figure 7. The structure of MANFIS

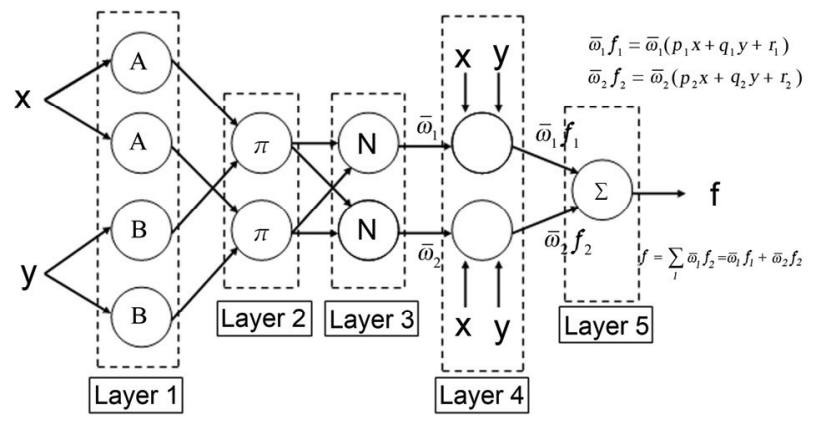

Figure 8. Five-layer structure of ANFIS

system (FIS) implemented in the framework of an adaptive fuzzy neural network. FIS is the process of formulating the mapping from a given input to an output using fuzzy logic.

ANFIS is based on Tagaki-Sugeno FIS. ANFIS gener- ally has two inputs, one output and its rule base contains two fuzzy if-then rules:

Rule 1: If $x$ is $A_{1}$ and $y$ is $B_{2}$ then $f_{l}=p_{1}+q_{1}+r_{l}$.

Rule 2: If $x$ is $A_{2}$ and $y$ is $B_{2}$ then $f_{2}=p_{2}+q_{2}+r_{2}$.

The five-layered structure of this ANFIS is depicted in Figure 8. The detailed description about it can refer to the studies by R. Jang et al. [34-37]. Here, by using the training data sets in Table 6 and through thirty times of training, the errors of the unknown constants in each node of MANFIS have been convergent.

\section{Analysis and Discussion}

For a complete-trained inverse model that is charac- terized with the inverse function of the simulator Moldex3D as well as manufacturing platform. That is, the manufacturing parameters can be found by the product required inversely. Here, the correlations between two kinds of product required and one manufacturing parameter are shown by 3D mesh diagrams in Figure 9. In addition to identify the reasonable areas for product required, the limits to the four important factors in the real case are set as following; mold temperature: over $40^{\circ} \mathrm{C}$, material temperature: over $210^{\circ} \mathrm{C}$, injection pre- ssure: over $90 \mathrm{Mpa}$, holding time: the smaller warpage the better.

Moreover, for the convenience in observation, the reasonable intervals of each product required are summarized in Table 7.

In order to confirm the reliability and preciseness of inverse model, two groups of numerical comparisons are made as shown in Table 8. Here, by comparing with the inputs of inverse model with the outputs of simulator which are corresponding to the outputs of inverse model, the differences between them are tolerably small. This appropriate performance of inverse model also can be observed in Figure 10.

Table 7. Reasonable intervals for product requirements

\begin{tabular}{ccccc}
\hline $\begin{array}{l}\text { factor } \\
\text { required }\end{array}$ & $\mathrm{B}$ & $\mathrm{C}$ & $\mathrm{D}$ & $\mathrm{F}$ \\
\hline $\mathrm{X}(\mathrm{mm})$ & $0.302 \sim 0.65$ & $0.302 \sim 0.65$ & $0.302 \sim 0.4$ & $0.302 \sim 0.5$ \\
$\mathrm{Y}(\mathrm{mm})$ & $-0.05 \sim 0.05$ & $-0.025 \sim 0.075$ & $-0.05 \sim 0.05$ & $-0.05 \sim 0.1$ \\
$\mathrm{Z}(\mathrm{mm})$ & $-0.15 \sim 0.008$ & $-0.175 \sim 0.008$ & $-0.1 \sim 0.008$ & $-0.15 \sim 0.008$ \\
$\mathrm{~V}(\%)$ & 4 & 4 & 4 & 4 \\
\hline
\end{tabular}

Table 8. Reliability performance of inverse model

\begin{tabular}{|c|c|c|c|c|c|c|c|c|c|c|c|c|}
\hline \multirow{3}{*}{ group } & \multicolumn{8}{|c|}{ Inverse Model } & \multirow{2}{*}{\multicolumn{4}{|c|}{$\frac{\text { Simulator Moldex3D }}{\text { Output }}$}} \\
\hline & \multicolumn{4}{|c|}{ Input } & \multicolumn{4}{|c|}{ Output } & & & & \\
\hline & $\mathrm{X}$ & $\mathrm{Y}$ & Z & $\mathrm{V}$ & B & $\mathrm{C}$ & $\mathrm{D}$ & $\mathrm{F}$ & $\mathrm{X}$ & $\mathrm{Y}$ & Z & $\mathrm{V}$ \\
\hline 1 & 0.302 & 0.09 & 0.008 & 4 & 220 & 126 & 7.26 & 43.4 & 0.504 & 0.012 & -0.102 & 3.851 \\
\hline 2 & 0.302 & 0.09 & -0.07 & 4 & 215 & 108 & 6.28 & 57.9 & 0.346 & 0.016 & -0.028 & 3.738 \\
\hline
\end{tabular}


need:above $210^{\circ} \mathrm{C}$

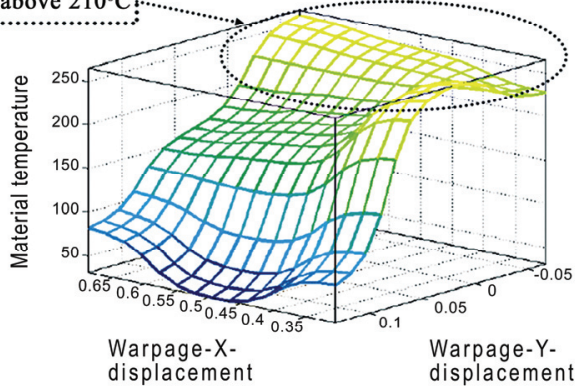

a. warpage- $\mathrm{x}$-displacement and warpageydisplacement to material temperature.

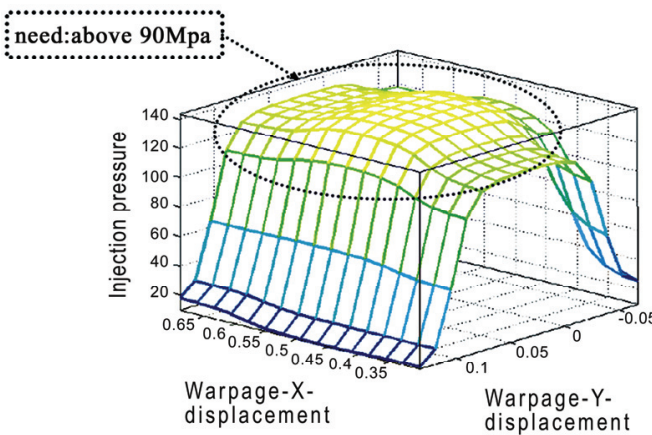

c. warpage-X-displacement and warpage-

y-displacement to injection pressure.

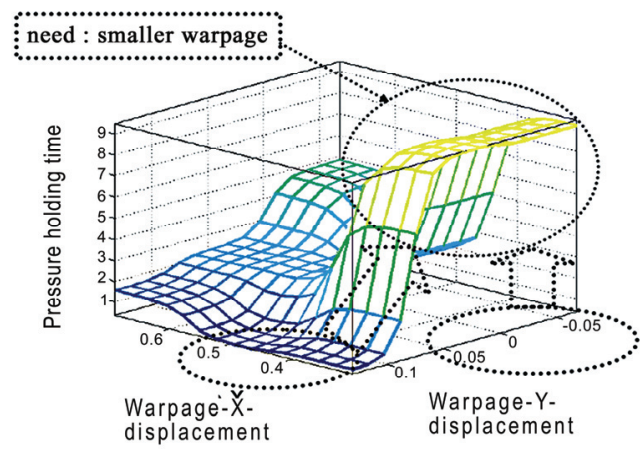

e. warpage-X-displacement and warpage$\mathrm{y}$-displacement to pressure holding time.

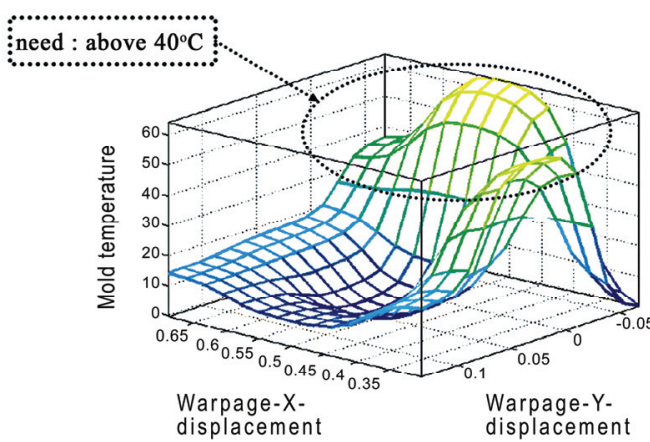

g. warpage-X-displacement and warpagey-displacement to mold temperature.

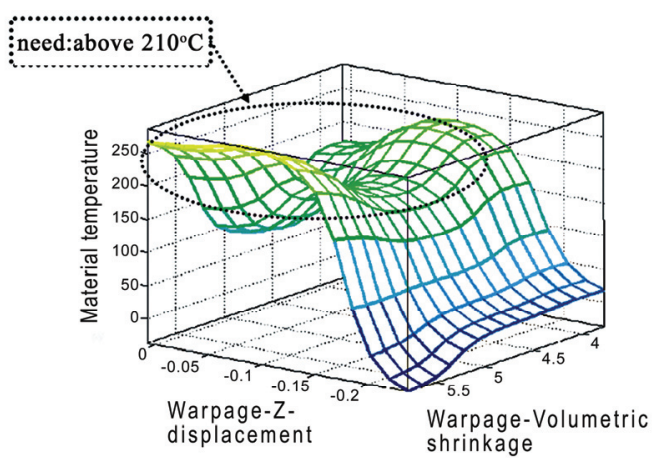

b. warpage-z-displacement and warpage-volumetric-shrinkage to material temperature.

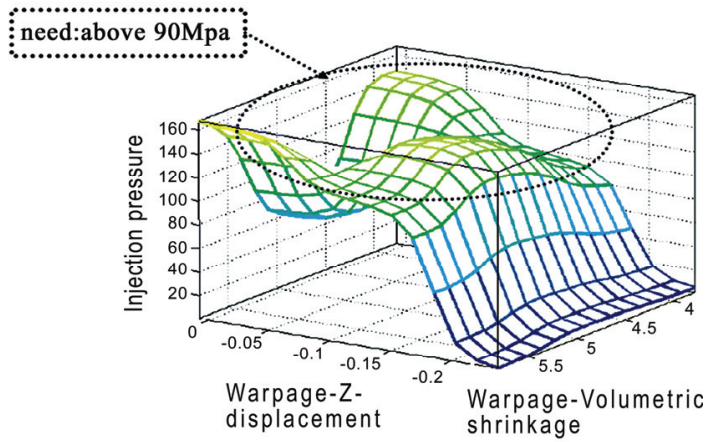

d. warpage-z-displacement and warpagevolumetric-shrinkage to injection pressure.

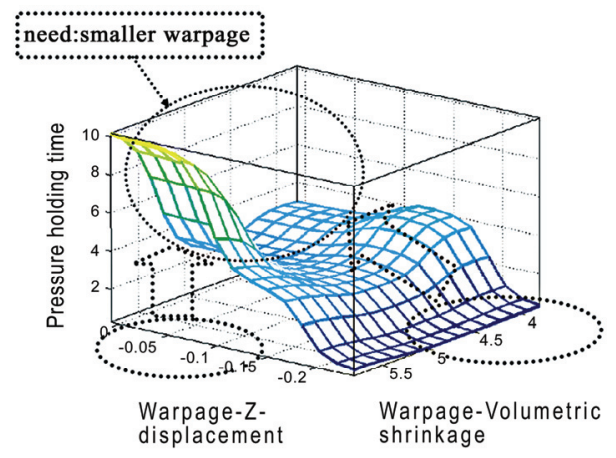

f. warpage-z-displacement and warpagevolumetric-shrinkage to pressure holding time.

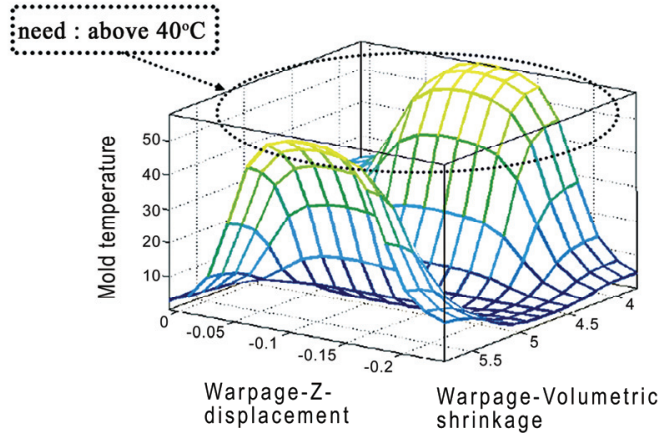

h. warpage-z-displacement and warpagevolumetric-shrinkage to mold temperature.

Figure 9. Correlations between two product requirements and one manufacturing parameter in 3D mesh diagrams 
Table 9. Optimized comparisons between Taguchi method and proposed method

\begin{tabular}{|c|c|c|c|c|}
\hline method factor & B & $\mathrm{C}$ & $\mathrm{D}$ & $\mathrm{F}$ \\
\hline Taguchi method & $220^{\circ} \mathrm{C}$ & 130Mpa & $8 \mathrm{~s}$ & $55^{\circ} \mathrm{C}$ \\
\hline Proposal & $215^{\circ} \mathrm{C}{ }^{\circ} \mathrm{C}$ & $108 \mathrm{Mpa}$ & $6.28 \mathrm{~s}$ & $57.9^{\circ} \mathrm{C}$ \\
\hline $\begin{array}{l}\text { requirement } \\
\text { method }\end{array}$ & $\mathrm{X}$ & $\mathrm{Y}$ & $\mathrm{Z}$ & $\mathrm{V}$ \\
\hline Taguchi method & $0.46 \mathrm{~mm}$ & $0.09 \mathrm{~mm}$ & $0.008 \mathrm{~mm}$ & $3.79 \%$ \\
\hline Proposal & 0.346 & 0.016 & -0.028 & $3.74 \%$ \\
\hline
\end{tabular}

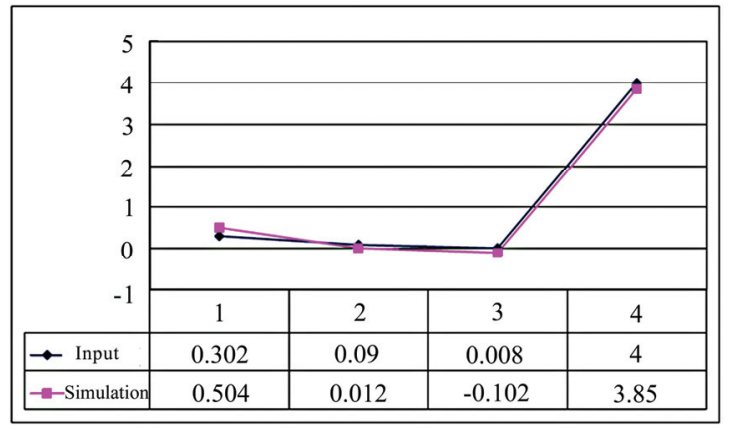

a. Group 1

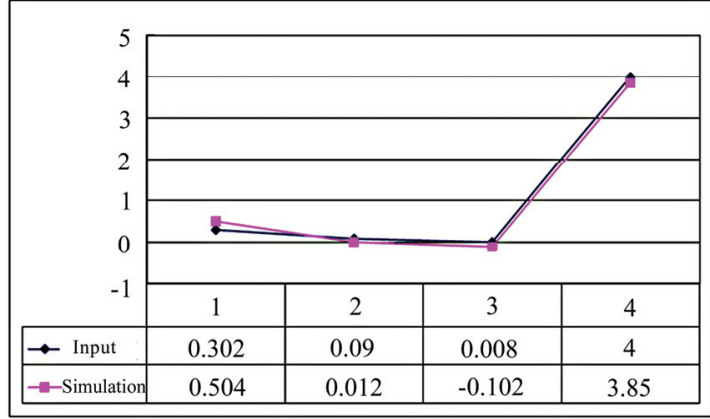

b. Group 2

Figure 10. Reliability performance of inverse model by two groups of data

As mentioned above, although it is easy to find out the optimal manufacturing conditions subjected to single quality required by Taguchi method, in the situation of requiring multiple qualities simultaneously, it is difficult to cope with the problem. Besides, for the changing levels of each controllable factor are ambiguous, it is possible to trap the solution in local optimum. The results are shown in Table 9 just can respond above problem. Where, by examining the manufacturing factors and product required found by Taguchi method and the proposed method, respectively, it can be found that the performance of proposed method is better than that done by Taguchi method.

\section{Conclusions}

For solving the optimal problem in manufacturing design of injection mold, the method basing on the concept of inverse model is proposed in this paper. Through the method, the optimal manufacturing parameters can be found by using the product required inversely. In addition, the effectiveness and appropriateness of the proposal are confirmed by the numerical studies on the real case. Yet the studied results show that the proposed method not only can improve the insufficiencies of Taguchi method but also offers a more précising and concise approach for the optimization of manufacturing design.

\section{Acknowledgments}

The authors would like to thank Prof. F.B. Hsiao, who is with the Department of Aeronautics and Astronautics at National Cheng Kung University, for his providing valuable real data for this study.

\section{REFERENCES}

[1] S. N. Huang; K. K. Tan and T. H. Lee, "Neural-networkbased predictive learning control of ram velocity in injection molding," IEEE Transactions on Systems, Man, and Cybernetics, Part C: Applications and Reviews, Vol. 34, Issue 3, pp. 363-368, August 2004.

[2] R. C. Luo and J. H. Tzou, "The development of direct metallic rapid tooling system," IEEE Transactions on Automation Science and Engineering, Vol. 4, Issue 1, pp. 1-10, January 2007.

[3] R. C. Luo, and Y. L. Pan, , "Rapid manufacturing of intelligent mold with embedded microsensors," IEEE/ ASME Transactions on Mechatronics, Vol. 12, Issue 2 , pp. 190-197, April 2007.

[4] Y. K. Shen and H. W. Chien, "Optimization of the micro-injection molding process using grey relational analysis and moldflow analysis," Journal of Reinforced Plastics Composites, Vol. 23, pp. 1799-1814, 2004.

[5] H. Qiao, "A systematic computer-aided approach to cooling system optimal design in plastic injection molding," International Journal of Mechanical Science, Vol. 48, pp. 430-439, 2006.

[6] J. M. Castro, M. Cabrera-R'1os, and C. A. Mount-Campbell, "Modelling and simulation in reactive polymer processing," Modelling and Simulation in Materials Science and Engineering, Vol. 12, pp. S121-S149, 2004.

[7] H. S. Yan, and D. Xu, "An approach to estimating product design time based on fuzzy $v$-support vector machine," IEEE Transactions on Neural Networks, Vol. 18, Issue 3, pp.721-731, May 2007.

[8] B. Ribeiro, "Support vector machines for quality monitoring in a plastic injection molding process," IEEE Transactions on Systems, Man, and Cybernetics, Part C: Applications and Reviews, Vol. 35, Issue 3, pp. 401-410, August 2005.

[9] M. Cabrera-R'1os, J. M. Castro, and C. A. Mount-Campbell, "Multiple quality criteria optimization in in-mold 
coating (IMC) with a data envelopment analysis approach," Journal of Polymer Engineering, Vol. 22, No. 5, pp. 305-340, 2002.

[10] M. Cabrera-R'10s, J. M. Castro, and C. A. Mount-Campbell, "Multiple quality criteria optimization in reactive in-mold coating with a data envelopment analysis approach: II. A case with more than three performance measures," Journal of Polymer Engineering, Vol. 24, No. 4, pp. 435-450, 2004.

[11] C. E. Castro, M. Cabrera-R'1os, B. Lilly, J. M. Castro, and C. A. Mount-Campbell, "Identifying the best compromises between multiple performance measures in injection molding (IM) using data envelopment analysis (DEA)," Journal of Integrated Design and Process Science, Vol. 7, No. 1, pp. 78-86, 2003.

[12] D. E. Smith, D. A. Tortorelli, and C. L. Tucker, "Analysis and sensitivity analysis for polymer injection and compression molding," Computer Methods in Applied Mechanics and Engineering, Vol. 167, pp. 325-344, 1998.

[13] A. Gokce, K. T. Hsiao, and S. G. Advani, "Branch and bound search optimization injection gate locations in liquid composite molding processes," Composites A, Vol. 33, pp. 1263-1272, 2002.

[14] D. E. Smith, "Design sensitivity analysis and optimization for polymer sheet extrusion and mold filling processes," International Journal for Numerical Methods in Engineering, Vol. 57, pp. 1381-1411, 2003.

[15] J. K. L. Ho, K. F. Chu, and C. K. Mok, "Minimizing manufacturing costs for thin injection molded plastic components," International Journal of Advanced Manufacturing Technology, Vol. 26, pp. 517-526, 2005.

[16] N. R. Subramanian, L. Tingyu, and Y. A. Seng, "Optimizing warpage analysis for an optical housing," Mechatronics, Vol. 15, pp. 111-127, 2005.

[17] G. Courbebaisse and D. Garcia, "Shape analysis and injection molding optimization," Computational Materials Science., Vol. 25, pp. 547-553, 2002.

[18] K. Alam and M. R. Kamal, "A robust optimization of injection molding runner balancing," Computers and Chemical Engineering, Vol. 29, pp. 1934-1944, 2005.

[19] S. Dowlatshahi, "An application of design of experiments for optimization of plastic injection molding processes," Journal of Manufacturing Technology Management, Vol. 15, pp. 445-454, 2004.

[20] S. J. Liu and Y. S. Chen, "The manufacturing of thermoplastic composite parts by water-assisted injection-molding technology," Composites A, Vol. 35, pp. 171-180, 2004.(water-assisted)

[21] C. P. Fung, "Multi-response optimization of impact performances in fiber-reinforced poly (butylene terephthalate)," Journal of Thermoplastic Composite Materials, Vol. 19, pp. 191-205, 2006. (fiber)

[22] C. P. Fung and P. C. Kang, "Multi-response optimization in friction properties of PBT composites using Taguchi method and principal component analysis," Journal of Materials Processing Technology., Vol. 170, pp. 602-610, 2005.(T)

[23] C. H. Wu and Y. L. Su, "Optimization of wedge-shaped parts for injection molding and injection compression molding," International Communications in Heat and Mass Transfer, Vol. 30, pp. 215-224, 2003.

[24] S. J. Liu, C. H. Hsu, and C. Y. Chang, "Parametric characterization of the thin-wall injection molding of thermoplastic composites," Journal of Reinforced Plastics Composites, Vol. 21, pp. 1027-1041, 2002.

[25] H. P. Heim, "The statistical regression calculation in plastics processing-Process analysis, optimization and monitoring," Macromolecular Materials and Engineering, Vol. 287, pp. 773-783, 2002. (R)

[26] H. Kurtaran and T. Erzurumlu, "Efficient warpage optimization of thin shell plastic parts using response surface methodology and genetic algorithm," International Journal of Advanced Manufacturing Technology, Vol. 27, pp. 468-472, 2006.

[27] B. Ozcelik and T. Erzurumlu, "Comparison of the warpage optimization in the plastic injection molding using ANOVA, neural network model and genetic algorithm," Journal of Materials Processing Technology, Vol. 171, pp. 437-445, 2006.(N)

[28] C. P. Fung, "The study on the optimization of injection molding process parameters with gray relational analysis," Journal of Reinforced Plastics Composites, Vol. 22, pp. 51-66, 2003.(G)

[29] S. H. Chang, J. R. Hwang, and J. L. Doong, "Optimization of the injection molding process of short glass fiber reinforced polycarbonate composites using grey relational analysis," Journal of Materials Processing Technology, Vol. 97, pp. 186-193, 2000.(G glass fiber)

[30] G. A. Vagelatos, G. G. Regatos, and S. G. Tzafestas, "Incremental fuzzy supervisory controller design for optimizing the injection molding process," Expert Systems with Applications, Vol. 20, pp. 207-216, 2001.(F)

[31] M. S. Phadke, "Quality Engineering Using Robust Design," Englewood Cliffs, NJ: Prentice-Hall, 1989.

[32] D. C. Montgomery, "Design and Analysis of Experiments," New York: Wiley, 1991.

[33] S. H. Park, Robust Design and Analysis for Quality Engineering. London, U.K.: Chapman \& Hall, 1996.

[34] R. Jag. , "Neuro-fuzzy modeling architectures, analysis and applications," PhD Thesis University of California, Bcrkley, July 1992.

[35] Zhang, J.; Shu-Hung Chung, H.; Wai-Lun Lo, "Chaotic time series prediction using a neuro-fuzzy system with time-delay coordinates," IEEE Transactions on HKnowledge and Data EngineeringH, Vo. 20, HIssue 7H, pp. 956-964, July 2008.

[36] Hinojosa, J.; Domenech-Asensi, G., "Multiple adaptive neuro-fuzzy inference systems for accurate microwave CAD applications," HCircuit Theory and Design, ECCTD'07. 18th European Conference onH, pp.767-770, August $27^{\text {th }}-30^{\text {th }}, 2007$.

[37] G. Domenech-Asensi, J. Hinojosa, R. Ruiz, J.A, DiazMadrid, "Accurate and reusable macromodeling technique using a fuzzy-logic approach," IEEE International Symposium on Circuits and Systems, ISCAS'08, pp.508-511, May $18^{\text {th }}-21^{\text {st }}, 2008$. 